\title{
NOVAS OCORRÊNCIAS DE EUCLÁSIO EM MINAS GERAIS
}

\author{
M.L.S.C.Chaves \& J.Karfunkel
}

PALAVRAS-CHAVE: euclásio, mineralogia, gemologia, aluviōes diamantiferos.

CHAVES, M.L.S.C.; KARFUNKEL, J. (1994) Novas ocorrências de euclásio em Minas Gerais. Bol.IG-USP, Sér.Cient., 25:53-60.

\section{RESUMO}

Desde o século XVIII o Brasil tem sido o principal produtor mundial de euclásio, proveniente das jazidas situadas nos arredores de Ouro Preto, Minas Gerais. Recentemente, três novos depósitos deste mineral foram descobertos no mesmo Estado: (1) Em 1979-80, garimpeiros explotaram cerca de $10 \mathrm{~kg}$ de material gemológico e de coleçăo. A situaçăo geográfica deste depósito permaneceu desconhecida na literatura geológica; ele está localizado próximo do vilarejo de Olhos d'Água, município de Bocaiúva, noroeste de Minas Gerais. (2) Pouco tempo após, uma outra ocorrência foi descoberta na mesma região, a cerca de $25 \mathrm{~km}$ NNW da cidade de Itacambira, de onde foram extraidos 3 $\mathrm{kg}$ de euclásio, a maior parte para coleção. (3) As ocorrências de Gouveia foram detectadas pelos autores, durante prospeç̧ão aluvionar sistemática visando o conhecimento de minerais "satélites" do điamante na região, mas os espécimens encontrados têm somente importância mineralógica. Em todas as situaçōes descritas, o mineral ocorre disseminado e/ou concentrado em bolsóes relacionados a uma estreita zona feldspática de veios de quartzo pegmatóides, cortando quartzitos do Supergrupo Espinhaço (Bocaiúva e Itacambira), ou xistos e rochas graníticas do Complexo Pré-Espinhaço (Gouveia).

\section{ABSTRACT}

Since the 18 th century euclase in Brazil has been mined mainly in the reknowed mineralogical district of Ouro Preto, Minas Gerais. Three new deposits were more recently discovered in the same state: (1) In 1979-80 garimpeiros exploited about $10 \mathrm{~kg}$ of yellow gem-quality material and specimens for collectors, but the location of the source remained unknown in the geologic literature. It is situated near the small village of Olhos D'Água, in Bocaiúva district, northwestern Minas Gerais; (2) Soon after the first exploitation, another euclase occurrence was discovered in the same region, some 25 $\mathrm{km}$ NNW of Itacambira. About $3 \mathrm{~kg}$ de grey-blue cuclase, mostly collection specimens, have been produced. (3) Occurrences in the Gouveia district were detected by the authors during alluvial diamond prospecting. In this area the specimens have only mineralogical importance. In all localities, the mineral occurs disseminated and/or concentrated in pockets in the small feldspathic zone of pegmatoid quartz veins truncating quartzites of the Espinhaço Supergroup (Bocaiúva and Itacambira deposits) or schist and granitic rocks of the pre-Espinhaço Complex (Gouveia occurrences).

Instituto de Geociencias e Museu de História Natural, Universidade Federal de Minas Gerais, Belo Horizonte, Minas Gerais, Brasil. 


\section{INTRODUÇÃO}

$\mathrm{O}$ euclásio $\left[\mathrm{BeAl}\left(\mathrm{SiO}_{4}\right) \mathrm{OH}\right]$ é um mineral bastante raro na natureza, apresentando com frequência propriedades gemológicas. Desde o século XVIII, o Brasil destaca-se como o principal produtor mundial de euclásio. Em Minas Gerais, as jazidas clássicas deste mineral estão associadas às jazidas de topázio imperial na região de Ouro Preto. Euclásio de origem pegmatítica ocorre principalmente próximo de São Sebastião do Maranhão, na Fazenda Santana do Encoberto.

Recentemente os autores, pesquisando a natureza dos minerais pesados que acompanham o diamante na região centro-norte de Minas Gerais, descobriram três novas ocorrências de euclásio, localizadas em áreas dos municípios de Bocaiúva, Itacambira e Gouveia. Vários espécimens encontrados nas duas primeiras ocorrências apresentaram caracteristicas gemológicas.

0 presente estudo objetiva a descrição geológica e mineralógica destes três depósitos, assim como discutir sobre a presença desse mineral em áreas de contexto estratigráfico bastante diferentes, demonstrando assim 0 ainda limitado conhecimento acerca da metalogenia regional.

\section{EUCLÁSIO NO BRASIL}

Os depósitos de topázio imperial, incluindo provavelmente os de euclásio, foram descobertos na região de Ouro Preto por volta de 1760 . O célebre mineralogista Haủy descreveu primeiramente o euclásio em 1792 a partir de amostras da região, mas apenas Echwege (1822) localizou a proveniência do mineral ao identificá-lo em meio a um lote de topázios oriundos daquela área. $\mathrm{Na}$ atualidade são conhecidas oito áreas produtoras de euclásio no Brasil, algumas delas com várias ocorrências dis- tintas. A maioria dos depósitos está situada no Estado de Minas Gerais (Fig. 1).

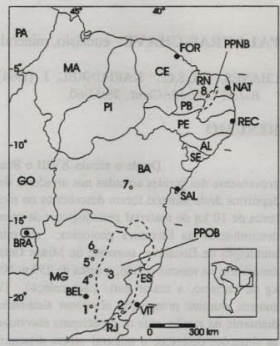

Figura 1 - Ocorrências de cuclásio no Brasil. 1, Regiẩo de Ouro Preto; 2, Cachoeiro de Santa Leopoldina; 3, São Sebastiāo do Maranhão; 4, Barào de Guaicui-Gouveia; 5, Bocaiúva; 6, Itacambira; 7, rio Paraguaçu; 8, Equador. Províncias pegmatiticas destacadas - PPOB, Provincia Pegmatítica Oriental Brasileira; PPNB, Provincia Pegmatitica Nordestina Brasileira.

As ocorrências clássicas e melhor conhecidas do Brasil e do mundo são aquelas localizadas em uma faixa linear de aproximadamente $10 \mathrm{~km}$ a oeste da cidade de Ouro Preto (MG). Nesta região o euclásio é recuperado como subproduto da garimpagem de topázio imperial em pelo menos sete lavras: Boa Vista, Trino, Ranchador, Capão do Lana, Fundão, Morro do Gabriel e Cachambu. O mineral ocorre em cristais isolados, transparentes a levemente azulados ou esverdeados, quase sempre de comprimento inferior a $1 \mathrm{~cm}$. Saldanha 
(1939) descreveu um espécime pesando $128 \mathrm{~g}$ (10 cm de comprimento) achado em 1922, provavelmente o maior cristal já conhecido. Descriçōes geológicas e mineralógicas sobre o euclásio de Ouro Preto foram apresentadas por Cassedanne $(1970,1991)$, mas sua gênese, assim como a do topázio, é objeto de amplas discussões.

Euclásio de origem pegmatítica ocorre em três principais localidades. Na região de São Sebastiāo do Maranhão (Fazenda Santana do Encoberto), também em Minas Gerais, o mineral se encontra em pequenos bolsões ricos em mica, perto do contato com o núcleo quartzoso do pegmatito (Cassedanne \& Cassedanne, 1974). Os cristais, com frequêencia biterminados, são incolores ou amarelados, transparentes a translúcidos, alcançando vários centímetros de comprimento. Este depósito já forneceu excelentes espécimes de qualidade-gema, descritos mineralogicamente por Bank (1974) e Graziani \& Guidi (1980). Proveniente de Cachoeiro de Santa Leopoldina, Estado do Espirito Santo, Saldanha (1941) relatou um cristal de euclásio, hialino e perfeitamente formado, mas sua jazida nunca foi descrita.

Pertencendo à Província Pegmatítica Nordestina do Brasil, são conhecidas ocorrências de euclásio associadas a quatro corpos pegmatíticos da região de Equador, Estado do Rio Grande do Norte. A presença de euclásio nesta área foi primeiramente referida por Silva \& Santos (1961), no denominado Alto dos Mamōes. Outros corpos pegmatiticos mineralizados são os "altos" do Giz, Santino e Jacu, onde ele ocorre com berilo junto ao núcleo de quartzo (Cassedanne, 1970). É característico dos cristais de euclásio de Equador uma listra azul escura central, paralela ao eixo c, permitindo belas amostras para coleção.

Hussak (1917) descreve ainda a presença de euclásio nos cascalhos diamantíferos de Santa Izabel do Paraguas- su, atual Mucugê (Estado da Bahia). Os espécimes, de interesse apenas mineralógico, eram cristais incolores e fragmentos de comprimento não superior a $3 \mathrm{~mm}$.

\section{DESCRIC̣ÃO DOS DEPÓSITOS}

Bank (1980), em pequena nota, descreveu um euclásio gema "declarado" ser da região de Diamantina, e Cassedanne (1991) citou que "pequenos cristais de euclásio bege a cinza foram recentemente extraídos na região de Buenópolis". Durante pesquisas incluindo o estudo de minerais pesados de cascalhos diamantiferos a leste de Bocaiúva, os autores foram informados de uma jazida desativada de euclásio na região, localizando assim o depósito que pelas amostras obtidas parece ser o mesmo relatado por H.Bank e J.Cassedanne. A partir de informações locais, chegou-se ao depósito de euclásio de Itacambira, explorado pelos mesmos garimpeiros descobridores da jazida anteriormente mencionada. Já as ocorrências de euclásio situadas próximo de Barão de Guaicuí, Gouveia, foram achadas diretamente pelos autores, durante prospecção aluvionar sistemática voltada para os minerais "satélites" do diamante; os depósitos primários estão sendo ainda pesquisados.

\section{Contexto geológico regional}

As três ocorrências de euclásio ora descritas estão relacionadas geologicamente à Serra do Espinhaço, onde este mineral nunca havia sido antes reportado. A serra é sustentada por quartzitos e filitos do Supergrupo Espinhaço, do Mesoproterozóico, localmente aflorando xistos e rochas granitóides de idade mais antiga (Complexo Pré-Espinhaço). A Faixa Móvel Espinhaço é uma entidade geotectônica evoluída durante o Meso e Neoproterozóico, com o clímax dos dobramentos, incluindo a 
intrusão de inúmeros veios de quartzo, tendo ocorrido no Ciclo Brasiliano (Dossin et al., 1990).

\section{Jazida do Buriti das Porteiras}

Situada a cerca de $12 \mathrm{~km}$ a SW do povoado de Olhos d'Água, Município de Bocaiúva (Fig. 2), a jazida do Buriti das Porteiras foi descoberta casualmente em 1979, durante a exploração de um veio de quartzo hialino, do tipo "coleção". Foi explorada em dois periodos (197980 e 1983) pelo garimpeiro Marcolino Pereira da Silva (vulgo "Pingo"), de Bocaiúva.

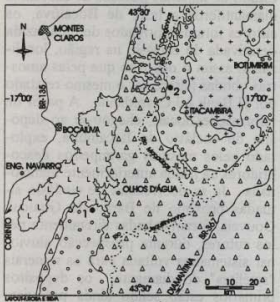

LOCNIZACIO DANAEANO
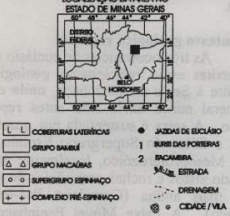

Figura 2 - Contexto geológico regional e localizaçăo dos depósitos de euclásio do Buriti das Porteiras (Bocaiúva) e de Itacambira.
Ocorrem na área quartzitos avermelhados, fortemente recristalizados e silicificados, atribuidos à Formação Gatho do Miguel, do Supergrupo Espinhaço (Schmidt, 1970). O euclásio está associado à zona de borda, caolinizada, de um veio de quartzo com hematita, de cerca de $10 \mathrm{~m}$ de comprimento por $2 \mathrm{~m}$ de largura, cortando os quartzitos. 0 mineral ocorre disseminado e/ou concentrado em pequenos bolsões. $\mathrm{O}$ material secundário, elúvio-coluvionar, foi também objeto de exploração.

O euclásio aparece em cristais euédricos a subédricos, de coloração amarelada clara a média, raramente terminados. Espécimens de qualidade gema são comuns, tendo Bank (1980) destacado que o depósito forneceu uma pedra com $50 \mathrm{ct}$, depois de lapidada. 0 maior cristal observado media $6 \mathrm{~cm}$ de comprimento ao longo do eixo $c$ $(55,6 \mathrm{~g})$. A clivagem $(010)$ perfeita é caracteristica de todas as amostras estudadas. 0 peso específico, medido em 8 amostras, é de $3,095 \pm 0,010 \mathrm{~g} / \mathrm{cm}^{3}$, e os indices de refração menor e maior são 1,651 e 1,671 \pm 0.001 com uma birrefringência de $0,020 \pm 0,001$.

Ainda nāo está bem caracterizada a gênese da jazida do Buriti das Porteiras. A presença de feldspatos caolinizados junto ao veio de quartzo sugere atividade pegmatítica, muito embora esta seja bastante incomum ao longo da Serra do Espinhaço. Nenhum outro mineral pegmatítico foi observado. O potencial do depósito é também pouco conhecido, já que as escavações não ultrapassaram 1,5 $\mathrm{m}$ de profundidade. Informaçőes obtidas do garimpeiro "Pingo" indicaram uma produção total de $12 \mathrm{~kg}$ (9 kg em 1979-80 e $3 \mathrm{~kg} \mathrm{em} \mathrm{1983,} \mathrm{estes}$ em parte recuperados a partir dos rejeitos anteriores).

\section{Jazida de Itacambira}

Este depósito está situado a cerca de $25 \mathrm{~km}$ norte-noroeste da pequena 
cidade de Itacambira, próximo às cabeceiras do Rio Congonhas. Em 1980, o mesmo decobridor da jazida do Buriti das Porteiras chegou a este local partindo da informação de um companheiro de garimpo, dizendo ter conhecido material "semelhante" ao lhe mostrado, enquanto procurava quartzo naquela porção da Serra do Espinhaço.

Geologicamente a região é conhecida como Espinhaço Central, tendo sido mapeada por Karfunkel \& Karfunkel (1976). Predominam na área quartzitos brancos, finos e bem selecionados, atribuidos à Formação Resplandecente. $\mathrm{O}$ euclásio ocorre em uma cascalheira coluvionar de espessura inferior a $1 \mathrm{~m}$, junto com quartzo e hematita.

Dados mineralógicos de amostras aparentemente "limpas" são os seguintes: peso específico ( 5 amostras) de $3,065 \pm 0,02 \mathrm{~g} / \mathrm{cm}^{3}$ e índices de refração 1,650 e $1,670 \pm 0,001$ com uma birrefringência de $0,020 \pm 0,001$. A coloração é sempre cinza-azulada, ao que parece como resultado de micro-inclusōes de turmalina preta (D.Hoover, 1993, comunic. verbal). E comum a presença de "bandas" preenchidas com quartzo segundo o plano (100); nestes casos o peso específico decai para $2,937 \pm 0,05$ $\mathrm{g} / \mathrm{cm}^{3}$.

Os cristais são sempre prismas euédricos tabulares, com $0,5-1,0 \mathrm{~cm}$ e sem terminação, possivelmente devido a um pequeno rolamento sofrido com ruptura na clivagem proeminente (010).

Estudos adicionais tornaram-se impossíveis, pois ao final da década de 80 a área de ocorrência foi recoberta com o plantio de eucaliptos para reflorestamento.

\section{Ocorrência de Barão de Guaicuí}

Durante prospecção aluvionar sistemática, desenvolvida na região de Diamantina com a finalidade de pesquisar minerais "satélites" do diamante (como parte da Tese de Doutoramento de um dos autores - M.L.S.C.C.), cristais de euclásio foram descobertos em dois locais: no Córrego do Capão e no Rio Pardo Pequeno. Eles estão situados a norte da cidade de Gouveia, nas proximidades do lugarejo de Barão de Guaicuí. Posteriormente à descoberta, entrevistas com garimpeiros locais permitiram constatar que o mineral é freqüente nestes aluviões diamantiferos, mas são confundidos com quartzo, apesar da densidade muito diferente. Alguns compradores de pedras admitiram mesmo terem comprado euclásio rolado como diamante, provavelmente devido ao forte brilho daquele mineral.

Nesta região afloram rochas pertencentes ao Complexo Pré-Espinhaço (sericita xistos e granitóides), além de metassedimentos da base do Supergnupo Espinhaço (formações São João da Chapada e Sopa Brumadinho). O Córrego do Capão, diamantífero, nasce na própria área, sendo por isso escolhido para a pesquisa de minerais pesados. A partir da detecção de euclásio no local, pesquisa suplementar efetuada na drenagem maior, Rio Pardo Pequeno, que já corre em terrenos da Formação Galho do Miguel (estratigraficamente superior), mostrou que a mineralização é persistente e que o maior aluvionamento permitiu também uma maior concentração do mineral (Fig. 3).

No aluvião estreito do Córrego do Capão, não ultrapassando $10 \mathrm{~m}$ de largura, o euclásio aparece em prismas relativamente bem preservados do desgaste mecânico, ainda exibindo com nitidez o estriamento paralelo ao eixo c. O maior exemplar observado mediu $0,8 \mathrm{~cm}$, sendo hialino como todos os cristais observados no local. Outros minerais presentes no depósito são mostrados na Tabela 1 .

No Rio Pardo Pequeno, os flats com larguras de 50 a $100 \mathrm{~m}$ permitiram a maior concentração de pesados. Os grãos de euclásio são mediana a total- 

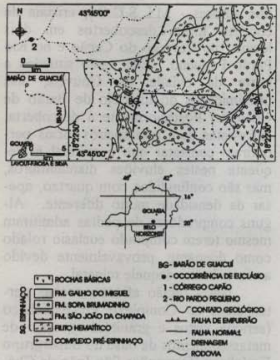

Figura 3 - Geologia e ocorrèncias de euclásio da área de Barão de Guaiacuí, município de Gouveia (modificado de Chaves \& Karfunkel, 1994).

Tabela 1 - Minerais pesados dos concentrados com euclásio na região de Gouveia (modificado de Chaves \& Karfunkel, 1993).

\begin{tabular}{|c|c|c|}
\hline Minerais & $\begin{array}{l}\text { rrego do } \\
\text { Capão }\end{array}$ & $\begin{array}{c}\text { Rio Pardo } \\
\text { Pequeno }\end{array}$ \\
\hline diamante & $\mathrm{x}$ & $\mathrm{x}$ \\
\hline lazulita & $\mathrm{x}$ & $\mathrm{x}$ \\
\hline rutilo & $\mathbf{x}$ & $x$ \\
\hline hematita & $x$ & $\mathrm{x}$ \\
\hline "favas" diversas & $\mathbf{x}$ & $\mathbf{x}$ \\
\hline cianita & $\mathrm{x}$ & $\mathrm{x}$ \\
\hline pirita limonitizada & $x$ & $x$ \\
\hline turmalina preta & $\mathbf{x}$ & $\mathbf{x}$ \\
\hline magnetita & $\mathrm{x}$ & $\mathrm{x}$ \\
\hline anatásio & $\mathbf{x}$ & $\mathbf{x}$ \\
\hline diásporo & $\mathrm{x}$ & \\
\hline moscovita & $\mathbf{x}$ & \\
\hline pirita & $\mathbf{x}$ & $\mathbf{x}$ \\
\hline espessartita & & $\mathbf{x}$ \\
\hline almandina (?) & $\mathbf{x}$ & \\
\hline
\end{tabular}

mente rolados, mostrando sempre um achatamento característico segundo o plano principal de clivagem (010). O maior cristal observado mediu $1,2 \mathrm{~cm}$ de comprimento. Em geral eles são incolores, transparentes e macroscopicamente "limpos"; em apenas um grão muito rolado observou-se uma tonalidade rosada.

O peso específico, obtido de 5 amostras do Córrego do Capão, mostrou valores em torno de $3,09 \pm 0,02$ $\mathrm{g} / \mathrm{cm}^{3}$. Dados ópticos determinados com refratômetro mostraram valores limites de 1,650 e 1,671, com uma dupla refração de 0,021 . Os índices de refração superiores àqueles do quartzo, associado ao brilho perláceo nas proximidades dos planos de clivagem (open cleavage), é a razão do mineral já ter sido confundido com diamante. Amostras roladas de euclásio do Rio Pardo Pequeno foram também confirmadas por difratometria de raios X.

Os euclásios das duas localidades descritas demonstraram uma associação de caracteristicas que permitem considerá-los de mesma origem. No Córrego do Capão, as amostras muito pouco roladas evidenciam sua fonte próxima, o contrário acontecendo no Rio Pardo Pequeno. Pesquisas procurando a possivel rocha fonte na área do Córrego do $\mathrm{Ca}$ pão, indicaram a existência de veios pegmatóides de porte inferior a $1 \mathrm{~m}$, cortando principalmente micaxistos do Complexo Pré-Espinhaço. Amostragem efetuada na massa caolinizada dos veios revelou apenas a presença de quartzo, mica e turmalina preta. Porém, o pequeno volume amostrado, associado à raridade do euclásio e às semelhanças com os depósitos de Bocaiúva (aqui descrito) e o de Santana do Encoberto (Cassedanne \& Cassedanne, 1974), permitem associar a gênese dos depósitos aos veios pegmatóides encaixados no Complexo Pré-Espinhaço. 


\section{CONSIDERAÇÕES FINAIS}

A presença de euclásio de origem pegmatítica em áreas com pouca ou nenhuma referência da presença desse tipo de atividade magmática, demonstra o ainda limitado conhecimento acerca da metalogenia regional. As pesquisas até então desenvolvidas permitem que sejam reconhecidos três tipos de depósitos primários de euclásio no Brasil:

(1) Na designada "litomarga" do distrito de Ouro Preto, uma argila marrom escura, de origem controvertida, associado ao topázio imperial,

(2) Em pegmatitos heterogêneos, bem zonados e relacionados a uma fase de magmatismo bem conhecida, datada no final do Brasiliano (550-450 Ma), como nos casos de Santana do Encoberto (MG), Cachoeiro de Santa Leopoldina (ES) e nos depósitos do Rio Grande do Norte, e

(3) Em veios pegmatóides, relacionados a processos magmáticos ainda pouco estudados na região da Serra do Espinhaço, dos quais são exemplos os depósitos de Bocaiúva, Itacambira e Gouveia, Minas Gerais, além de, provavelmente, as pouco conhecidas ocorrências da Chapada Diamantina, no centronorte baiano.

\section{REFERÊNCIAS BIBLIOGRÁFICAS}

BANK, H. (1974) Euklase von Santana do Encoberto, Minas Gerais, Brasilien. Aufschluss, v.25, n.9, p.445448.

BANK, H. (1980) Neues Vorkommen von Euklas in Brasilien. Zeitschrift der Deutschen Gemmologischen Gesellschaft, v.29, p. 190.

CASSEDANNE, J.P. (1970) L'euclase au Brésil. Bulletin de la Association Française de Gemmologie, v. 24, p. 10-12.

CASSEDANNE, J.P. (1991) Tipologia das jazidas brasileiras de gemas. In: BRASIL. Departamento Nacional da Produção Mineral. Principais depósitos minerais do Brasil. Brasília, DNPM/CPRM. v. 4, p. 17-36.

CASSEDANNE, J.P.; CASSEDANNE, J.O. (1974) Mineral collecting localities from the Capelinha-Malacacheta Area (State of Minas Gerais, Brazil). Mineralogical Record, v.5, p.224232.

CHAVES, M.L.S.C.; KARFUNKEL, J. (1993) Euclásio na região de Gouveia, Minas Gerais. In: SIMPÓSIO DE GEOLOGIA NÚCLEO MINAS GERAIS, 7., Belo Horizonte, 1993. Anais. Belo Horizonte, SBG. p.115117.

DOSSIN, I.A; DOSSIN, T.M; CHAVES, M.L.S.C. (1990) Compartimentação estratigráfica do Supergrupo Espinhaço em Minas Gerais os grupos Diamantina e Conselheiro Mata. Revista Brasileira de Geociências, v.20, p.178-186.

ESCHWEGE, W.L.von (1822) Geognostisches Gemälde von Brasilien und wahrscheinliches Muttergestein der Diamanten. Landes-IndustrieComptoir, Weimar, 44p.

GRAZIANI, G.; GUIDI, G. (1980) Euclase from Santa do Encoberto, Minas Gerais, Brazil. American Mineralogist, v.65, p. 183-187.

HUSSAK, E. (1917) Os satélites do diamante. Rio de Janeiro, Serviço Geológico e Mineralógico do Brasil, 56p.

KARFUNKEL, $\mathrm{J}$; KARFUNKEL, B. (1976) Geologia da Serra do Espinhaço no norte de Minas Gerais (Itacambira-Botumirim). In: CONGRESSO BRASILEIRO DE GEOLOGIA, 31., Ouro Preto, 1976. Anais. Ouro Preto, SBG. v.2, p.169188.

SALDANHA, R. (1939) Sobre 0 euclásio de D.Bosco (Município de Ouro Preto). Boletim da Faculdade de Filosofia, Ciências e Letras da 
Universidade de São Paulo. Série Mineralogia, 3, v.17, p.29-37.

SALDANHA, R. (1941) Nota sobre o euclásio de Cachoeiro de Santa Leopoldina (Estado do Espirito Santo). Boletim da Faculdade de Filosofia, Ciências e Letras da Universidade de São Paulo. Série Mineralogia 4, v. 19 , p. 25-31.

SCHMIDT, H.L. (1970) Fazieswechsel in der jungproterozoischen São Francisco - Serie bei Bocaiuva, Espinhaço-Zone, Minas Gerais, Brasilien. Heidelberg, 32p. (Dissertation - Doktorat). Universität Heidelberg.

SILVA, R.R.; SANTOS, J.M.G. (1961) Sobre o euclásio de Parelhas (Rio Grande do Norte). Boletim do Instituto de Geologia. Série Mineralogia, n.1, p.5-19.

M.L.S.C.Chaves - Departamento de Geologia, IGC/UFMG, Av. Antônio Carlos, 6627, CEP 31270-010, Belo Horizonte, MG, Brasil. 